\title{
A EDUCAÇÃO ESPECIAL EM ESCOLAS REGULARES: tramas e dramas do cotidiano escolar
}

\author{
Special education in regular schools: \\ plots and dramas in everyday school life
}

\section{Katia Regina Moreno Caiado ${ }^{[a]}$, Larissa de Souza Martins ${ }^{[b]}$, Nicole Dragone Rosseto Antonio ${ }^{[c]}$}

[a]D ocente do Programa de Pós-G raduação em E ducação da Pontifícia Universidade Católica de São Paulo (PUC-SP), Campinas, SP - Brasil, e-mail: kaiado@ uol.com.br

${ }^{[b]}$ Bolsista de iniciação científica da Pontifícia Universidade Católica de São Paulo (PUC-SP), Campinas, SP - Brasil, e-mail: larysml@yahoo.com.br

${ }^{[c] B o l s i s t a ~ d e ~ i n i c i a c ̧ a ̃ o ~ c i e n t i ́ f i c a ~ d a ~ P o n t i f i ́ c i a ~ U n i v e r s i d a d e ~ C a t o ́ l i c a ~ d e ~ S a ̃ o ~ P a u l o ~}$ (PUC-SP), Campinas, SP - Brasil, e-mail: nicoledra@uol.com.br

\section{Resumo}

O objetivo desta pesquisa é contribuir com a reflexão sobre a formação de professores para atuarem com alunos deficientes nas séries iniciais do ensino fundamental e refletir sobre as práticas pedagógicas desenvolvidas nas denominadas classes inclusivas. Os dados empíricos foram construídos com fontes orais. Realizamos 102 entrevistas com professores que atuam nas séries iniciais do ensino fundamental, em sala regular de instituições de ensino regular, públicas ou privadas. Para análise e discussão dos dados utilizamos fontes bibliográficas e 
documentais, tais como: revisão bibliográfica, legislação, documentos de organismos nacionais e internacionais que abordam a temática em estudo. Assim, trabalhamos com eixos temáticos definidos a partir dos objetivos da pesquisa e dos conteúdos que emergiram das fontes. $\mathrm{O}$ foco deste trabalho é a formação do professor para atuar nas denominadas "classes inclusivas". Nessa direção, organizamos dados referentes ao ano letivo de 2006 sobre: 1. o número de alunos com deficiência matriculados em cada escola; 2. o tipo de deficiência; 3. o tipo de serviço de apoio educacional especializado existente na escola; 4. a formação do professor, inicial e continuada; 5. o tempo de magistério; 6. o tempo de magistério em salas "inclusivas"; 7. as práticas pedagógicas nas salas "inclusivas"; 8. as sugestões dos professores referentes à construção de uma escola inclusiva. O s resultados revelam: um significativo aumento de alunos com variados tipos de deficiências frequentando salas do ensino regular; um damor dos professores por formação centrada no processo de ensino-aprendizagem; as condições desfavoráveis de trabalho docente e vivência escolar.

Palavras-chave: Educação inclusiva. D eficiência. Práticas pedagógicas.

\begin{abstract}
The aim of this study is to contribute a reflection about the educational preparation of teachers for them to be able to deal with deficient students in the initial classes of fundamental education and about pedagogical practices developed in classes denominated as "inclusive". Empirical data was put together orally by means of 102 interviews of teachers who have initial regular classes in fundamental education in both public and private schools. In order to analyze and discuss the data, we used bibliographical and documentary sources like bibliographic reviews, legislation and documents from national and international organs that deal with the idea studied. Thus, we worked with thematic axises defined by the study's objectives and contents that came from the sources. The work focused on the preparation of teachers to actuate in classes denominated as "inclusive". In this sense, we organized data referring to the 2006 school year concerning: 1 . The number of deficient students in each school;2. Types of deficiency; 3. Type of support service for specialized
\end{abstract}

Rev. Diálogo Educ., Curitiba, v. 9, n. 28, p. 621-632, set./ dez. 2009 
education provided; 4 . The initial and continued preparation of the teachers; 5. Their time of service; 6. Their time of teaching in "inclusive" classrooms; 7. Pedagogical practice in "inclusive" classrooms; 8. Suggestions of the teachers regarding the creation of an "inclusive" school. Results revealed: a significant increase of students with diverse types of deficiencies in the regular school system; the urgent plea of teachers for providing training centered on the process of teaching-learning; and the deplorable working conditions of teachers and of the day-by-day school situation.

Keywords: Inclusive education. Deficiency. Pedagogical practice.

\section{INTRODUÇÃO}

A tualmente em nosso país, a formação de professores para educação especial encontra-se num grande impasse. As Diretrizes Curriculares Nacionais do Curso de Pedagogia, aprovadas pelo Conselho Nacional de Educação, não especificam como se dará a formação do professor especialista em educação especial e nem exigem a formação do professor capacitado; apenas apontam a inclusão como princípio educativo (SAVIANI, 2008). Nas demais licenciaturas, há uma recomendação ministerial que alerta sobre a necessidade da área da educação especial ser contemplada nesses cursos.

Assim, permanece o debate sobre o lócus de formação inicial do professor: seria no ensino médio ou no superior? Qual seria a formação do professor para trabalhar com alunos deficientes na sala regular? E qual a formação para o professor especialista? Sobre a formação do professor especialista em educação especial discute-se: ensino superior ou pósgraduação? (MICHE LS, 2008). D iferentes, e nem sempre avaliadas como positivas, propostas de formação continuada são implantadas, nas redes e universidades, para responder ao apelo de professores que legalmente são obrigados areceber o aluno deficientena classeregular, mas reivindicam orientação, uma vez que em sua formação não houve conteúdos ou disciplinas que abordassem essa nova organização da escola.

Paradoxalmente, aumenta o número de crianças e jovens com deficiência em idade escolar que procuram matrículas no ensino regular, assim como adultos com deficiência que ingressam em supletivos e cursos de alfabetização (BRASIL, 2008).

Rev. Diálogo Educ., Curitiba, v. 9, n. 28, p. 621-632, set./ dez. 2009 
Nesse quadro, urge problematizarmos as práticas sociais, as práticas pedagógicas, construídas nesse cotidiano escolar, analisá-las, compreendê-las na sua complexidade e múltiplas determinações para, então, subsidiar propostas de ação para a formação inicial e continuada de professores. Formação competente, que se comprometa com 0 acesso, a permanência e a apropriação de conhecimento para todos os alunos, inclusive os alunos com deficiência.

\section{A pesquisa}

Com o objetivo de problematizar a formação de professor para educação especial, no ensino superior, estabeleceu-se que uma etapa importante para coleta de dados neste estudo seria visitar escolas de ensino fundamental (de 1a a $4^{\underline{a}}$ série, públicas e particulares) onde houvesse alunos com deficiência regularmente matriculados e frequentando as aulas. Instituições com esse perfil têm sido denominadas neste município de "as escolas inclusivas".

A visita às escolas e as atividades de observação e entrevistas foram realizadas como parte do conteúdo ministrado na disciplina "Fundamentos de Educação Especial A", do 5ㅇsemestre do Curso de Pedagogia, turmas do matutino e noturno.

Nas visitas coletou-se dados referentes a:

1) o número de alunos com deficiência matriculados em cada escola;

2) o tipo de deficiência (conforme os professores entrevistados nomeiam o que entendem como sendo quem é o aluno com deficiência);

3) o tipo de serviço de apoio educacional especializado existente na escola;

4) a formação do professor, inicial e continuada;

5) o tempo de magistério;

6) o tempo de magistério em salas "inclusivas";

7) as práticas pedagógicas nas salas "inclusivas";

8) as sugestões dos professo res referentes à construção de uma escola inclusiva.

Rev. Diálogo Educ., Curitiba, v. 9, n. 28, p. 621-632, set./ dez. 2009 
Em todas as escolas houve professoras dispostas a serem entrevistadas e falarem sobre sua formação, sobre o tempo em que estão no magistério e sobre as práticas pedagógicas que desenvolvem no cotidiano das classes "inclusivas". A o final da entrevista, aúltima pergunta provocava a que dessem sugestões para a construção da escola inclusiva.

Ao falar sobre as práticas pedagógicas solicitava-se que discorressem sobre o planejamento das aulas, a preparação das atividades, a avaliação da aprendizagem, a interação professor-classe e a interação entre os alunos. Muitas professoras ainda falaram sobre sua relação com o professor especializado, a participação da comunidade escolar e a participação da família.

Assim, durante 0 ano letivo de 2006, 102 (cento e duas) escolas foram visitadas na região metropolitana de Campinas; sendo que 28 (vinte e oito) públicas estaduais, 35 (trinta e cinco) municipais e 39 (trinta e nove) particulares. Em cada escola um professor das séries iniciais do ensino fundamental, cuja classe tinha ao menos um aluno com deficiência matriculado e frequentando as aulas, foi entrevistado por uma aluna do Curso de Pedagogia. Portanto, foram entrevistados 102 professores (CAIAD O ; MARTINS; ANTÔNIO, 2007).

\section{Os dados analisados revelam que:}

- sobre a formação docente: $14 \%$ cursou apenas o magistério, 84\% cursou a graduação em pedagogia, 31\% especialização lato sensu, 4\% com mestrado e 0\% doutorado;

- sobre o tempo de magistério: variou de 6 meses a 27 anos nas escolas estaduais, 3 a 32 anos nas escolas municipais e 3 a 30 anos nas escolas particulares;

- sobre o número de matrículas: 803 (oitocentos e três) alunos com deficiência estavam matriculados na escola, sendo: 215 (duzentos e quinze) nas escolas estaduais, 412 (quatrocentos e doze) nas escolas municipais e 176 (cento e setenta e seis) nas escolas particulares;

- sobre os tipos de deficiência, os professores relataram que havia alunos com: deficiência visual, deficiência auditiva, deficiência motora, deficiência física, deficiências múltiplas,

Rev. Diálogo Educ., Curitiba, v. 9, n. 28, p. 621-632, set./ dez. 2009 
condutas típicas, síndrome de D own, síndrome de West, autismo, paralisia cerebral, hidrocefalia, distúrbios de aprendizagem, dislexia, convulsões, distúrbio de fala;

- sobre os serviços de apoio encontramos: salas de recurso, classes especiais, professores especializados, intérprete de Libras, professor auxiliar, acompanhamento com psicólogo, professora particular, acompanhamento com várias instituições e projetos.

D entre as entrevistadas, poucas são as professoras que nunca estudaram o tema da educação especial, seja na graduação, especialização ou cursos de extensão. O aumento de matrículas de alunos com deficiência na escola regular é uma realidade nacional, como revelam os dados oficiais (BRASIL, 2008). Neste estudo, a diversidade de tipos de deficiência chama muito a atenção, as denominadas dificuldades de aprendizagem cedem espaço para as deficiências sensoriais, mentais e físicas, ou seja, há nessas escolas um número significativo de alunos com sérios comprometimentos e muitos chegaram às escolas com idade avançada, sendo que o espaço familiar foi o único espaço de socialização; situações que requerem respostas rápidas e consistentes dos profissionais da escola e dentre eles, do professor especializado. No entanto, os serviços de apoio educacional especializado, quando há, nem sempre têm um professor com formação adequada, há normalistas, monitores, psicólogos, estagiários que realizam o denominado "apoio educacional especializado" em muitas escolas públicas e privadas. Ainda sobre os serviços de apoio educacional especializado há um ponto de forte tensão na área que se revela quando os professores da rede pública afirmam que esse serviço é oferecido em instituições especializadas, ou seja, verbas públicas são repassadas para instituições privadas onde se questiona se há acompanhamento sobre esse serviço, seja ele de supervisão ou orientação .

Sobre as práticas pedagógicas há relatos bem descritivos e outros lacônicos, em que o silêncio ou a digressão parecem confirmar que pouco se discute ou se concretiza no que se refereà apropriação do conhecimento. Afinal, o trabalho pedagógico não tem o processo deensino eaprendizagem como seu principal objetivo? D ados sobre o abandono da escola e sobre um preocupante número de alunos analfabetos concluindo o ensino fundamental é realidade nacional. 0 que confirma que para além de vagas e permanência na escola faz-se necessária a discussão sobre o papel da educação, seja ela uma escola onde háalunos com deficiência matriculados

Rev. Diálogo Educ., Curitiba, v. 9, n. 28, p. 621-632, set./ dez. 2009 
ou não. D entre as falas das professoras definimos dois eixos temáticos: 1 . apropostapedagógicada escola; 2.0 planejamento, as atividades propostas e a avaliação da aprendizagem.

- Sobre a proposta pedagógica da escola: as professoras relatam:

0 lha, 0 meu dia a dia é muito complicado, primeiro porque 0 sistema educacional é apostilado, depois é uma 2 asérie e a aluna não sabe nem ler e nem escrever. A gente acha que ela é autista, mas sem o laudo médico eu não posso separar as atividades... acho que estamos perdendo tempo (E P 3).

A indusão fica difícil quando se trabalha no método tradicional, mas a escola trabalha com o método Freinet e fica mais fácil. C ada aluno faz seu tempo e eu utilizo atividades diferenciadas (E P5).

A gente trabalha com ateliê. 0 trabalho já é diversificado para todas as crianças, visando mesmo atender a individualidade decada um. P or isso não tem plano especial para os "especiais", eles entram nessa coisa dos ateliês, cada um no seu ritmo... (E P25).

T rabalhar com alunos com alguma deficiência ex igealgumas adaptações, mas aqui 0 aluno é pesquisador. Ele procura seus próprios conhecimentos. L ógico que nós damos as coordenadas, orientamos, aproveitamos situações cotidianas, datas comemorativas e, principalmente, 0 dia a dia do aluno (E M 14).

0 E stado é assim: tem que ter inclusão, tem que ter a inclusão! A cho muito boa a inclusão, mas dentro de sala a gente tem que ter suporte. A inclusão está aí e você tem que aceitar. Tudo bem, a gente aceita. $\mathrm{M}$ as a gente também tem que saber trabalhar. 0 problema no E stado é que vem de cima para baix 0. A í, aqui embaix 0 você tenta se virar como pode. N ós professores somos os primeiros a receber o problema, mas os últimos a ter a solução, o como trabalhar com 0 problema (E E 19).

A escola não inclui esse aluno no planejamento. 0 planejamento é igual para todos. Q uem prepara as atividades para ela sou eu mesma, porque ela não acompanha nada do quea gente faz. A liás... ela só sabe desenhar e pintar (E E 25).

Rev. Diálogo Educ., Curitiba, v. 9, n. 28, p. 621-632, set./ dez. 2009 
Nessas falas as professoras revelam propostas pedagógicas que pouco se aliam à construção de um trabalho educacional que considere a diversidade. Teorias de educação traduzidas em apostilas, aulas não planejadas, conteúdos circunscritos ao cotidiano, alunos idealizados numa falsa homogeneidade e expostos a um único planejamento retiram do professor as decisões sobre o que estudar e o como ensinar. Esvaziam qualquer possibilidade de trabalho com um currículo onde o saber é vivo e construção sistematizada humana, onde os saberes dos alunos seriam ponto de partida para dimensões que ampliassem a curiosidade e o prazer de conhecer e interferir no mundo. Nessas propostas, o aluno com deficiência provavelmente engrossará os índices dos alunos que evadem da escola ou nela permanecem excluídos. Muitas vezes, permanecem na escola anos a fio e dela saem analfabetos, como revelam várias pesquisas ${ }^{1}$ atuais. $0 \mathrm{~s}$ excluídos do interior, como afirma Bourdieu (1997).

- Sobre o planejamento, as atividades propostas e a avaliação da aprendizagem: as professoras relatam:

0 planejamento das aulas é praticamente o mesmo dos demais alunos, pois a aluna (surda) a companha sem dificuldades. E la tem 0 apoio da família, acompanhamento psicológico, fonoaudióloga, psicopedagoga que comparece todos os meses para uma reunião. A aluna lế, produz pequenos tex tos... (E E 16).

Particularmente é complicado, tenho dificuldades elimitações. N ão sei 0 que planejar para ele (autista). 0 que ele faz são desenhos, rabiscos e gosta de brincar com blocos de madeira. E le pouco interage com os demais, porque 0 que ele faz é diferente dos outros. E le fica sozinho, brincando (E E 28).

A s aulas são planejadas pela professora da educação especial. É bom dizer que essas atividades já planejadas começaram este ano. A ntes eu produzia as atividades aleatoriamente, sem saber se estava correto (E M 1).

1 Ver produção do Grupo de Pesquisa: Inclusão/ exclusão escolar e desigualdades sociais. Disponível em: <http:/ / www.pucsp.br/ pos/ ehps/ >.

Rev. Diálogo Educ., Curitiba, v. 9, n. 28, p. 621-632, set./ dez. 2009 
0 planejamento ésempreelaborado em conjunto com as demais professoras do grupo e a orientadora pedagógica. Mas sem dúvida ex iste grande dificuldade de se adaptar o mesmo conteúdo na mesma sala, com duas realidades bem diferentes: as criancas tidas normais e as portadoras de algum tipo de deficiência (E M 2).

E le (síndrome de D own) não queria fazer atividades diferenciadas, mas a que todos os outros alunos estavam faz endo. A í passei a aplicar a mesma atividade para todos. E u e os alunos 0 ajudávamos, notei que fomos todos envolvidos no desenvolvimento dessa criança (E M 29).

Sobrea dinâmica da aula, antes dos alunos surdos, eu trabalhava com temas de discussão em roda. D epois fazíamos o registro. Isso abria espaço para a transdisciplinaridade. H oje, com os surdos, me sinto sem chão (E M 35).

G ente! $V$ ocês nem imaginam a trabalheira que él $\mathrm{E} u$ procuro fazer um monte de coisas...preparo atividades variadas e espero para ver 0 comportamento dele naquele dia. Ele é uma caixinha de surpresas (paralisia cerebral) (E P1).

E $m$ relação à avaliação, nada é feito, porque 0 E stado não repete mais nenhum aluno, por isso que ela está na 4 a série e não sabe nada: nem ler ou escrever, nem as letras e números ela reconhece! (E E -25).

Nessas falas as professoras revelam que háalunos com deficiência que aprendem o conteúdo escolar fora da escola e com isso, passam despercebidos durante as aulas. Háoutros que não incomodam tampouco, porque ficam ocupados e imersos em atividades repetitivas e solitárias. Nos relatos sobre as práticas de avaliação toca-se numa ferida dentro da escola: a progressão continuada. Novamente, há professoras que se referem ao alívio de terem especialistas que decidem sobre sua prática e outras que revelam os encantamentos que o trabalho pedagógico ainda traz, mesmo após 20 anos de magistério e em condições muitas vezes tão precárias. Mas na entrelinha dessas narrativas leio sobre a solidão dos alunos com deficiência em sala, leio sobre a solidão dos professores que os aceitam com tantas reservas, porque não sabem o que fazer com "0 aluno que lhe tira o chão." $\mathrm{Na}$ verdade, leio a distância que temos a percorrer na construção de um currículo que tome o conhecimento sobre a vida, que abra as dimensões da arte, da ciência, do movimento histórico e que considere os alunos sujeitos de direitos, sujeitos singulares.

Rev. Diálogo Educ., Curitiba, v. 9, n. 28, p. 621-632, set./ dez. 2009 
- Sobre as sugestões para construção de uma escola inclusiva.

As professoras falam sobre diferentes necessidades que devem ser atendidas, tais como formação e condições de trabalho. Na formação inicial afirmam a necessidade de oferecimento de conteúdos referentes à educação especial nas disciplinas do Curso dePedagogia; alguns professores afirmam a importância do tema ser conteúdo nos cursos de graduação de todas as áreas afins. Na formação continuada tanto solicitam formação antes de qualquer matrícula de aluno com deficiência (conhecimentos gerais, sensibilização) e formação sobre conteúdos específicos: como ensinar o aluno com deficiência que está matriculado em sua sala;

T em que se preparar no geral: como lidar, como falar com 0 aluno e com a família, como socializar e como promover a aceitação do grupo (E P1).

Curso de acompanhamento com profissional especializado: psicólogo, fonoaudiólogo, terapeutas... profissionais quepossam ajudar no aprendizado das crianças.... (E E 5).

C ursos para os professores aprenderem a se comunicar com eles etransmitir os seus conhecimentos (E E 6).

C ursos com professores especialistas que dessem palestras enos ensinassem a produzir material para que os alunos possam trabalhar (E M 7).

Seria conveniente que a U niversidade conhecesse os desafios da escola e oferecesse espaços de formação que atendessem essa realidade (E M 34).

No que se refere às condições de trabalho afirmam que seriam necessárias salas com um número menor de alunos, um limite de matrículas de alunos com deficiência por sala, materiais pedagógicos especializados e diversificados em sala de aula, recursos pedagógicos da informática, salas de recurso na escola para atendimento pedagógico ao aluno com deficiência e apoio ao professor na elaboração de atividades, ações pedagógicas coletivas na escola, presença de um outro adulto em sala deaula- professor assistente, professor ajudante, professor especializado, monitor ou estagiário. D entre as condições necessárias ao trabalho a de que se pensar nas condições que a escola oferece como, adaptações arquitetônicas: rampas, banheiros adaptados, acesso às quadras; adaptação de mobiliário; sinalização sensorial; formação para todos os profissionais da escola; reuniões gerais com todos

Rev. Diálogo Educ., Curitiba, v. 9, n. 28, p. 621-632, set./ dez. 2009 
os profissionais da escola para trocas de experiência e tomada de decisão coletiva; presença de um monitor para acompanhar o aluno com deficiência na escola. Afirmam ainda a necessária relação com profissionais da saúde para atendimento ao aluno, aos pais e aos professores. Todas essas sugestões apresentadas pelas professoras nas entrevistas realizadas aparecem como metasnosdiscursos oficiais, sejanalegislação (BRASIL, 2001), em documentos nacionais (BRASIL, 2008) ou documentos internacionais (ONU, 2006).

Interessante ainda registrar que sobre as condições de trabalho chama a atenção o fato de os professores não mencionarem a necessidade de valorização do trabalho docente, como se todos estivessem satisfeitos com seus salários. Pesquisa recente sobre a remuneração dos professores da rede estadual de São Paulo revela que os salários dessa categoria são baixos (D IEG UEZ , 2007). 0 que nos revela esse silêncio? Pode-se inferir que ainda há o sentimento de caridade diante da pessoa com deficiência?

\section{CONSIDERAÇÕES FINAIS}

O s resultados revelam que a maioria dos professores estudou o tema da educação especial, seja na formação inicial ou em serviço. Mesmo assim, surpreendeu a insistência com que afirmam a necessidade de formação docente como principal sugestão para a construção da escola inclusiva. Pode-se concluir que essa formação foi insuficiente? Não respondeu à complexidade que o cotidiano escolar revela?

É como um clamor: precisamos estudar e discutir como trabalhar com esse ou aquele aluno que tem determinada deficiência, como preparar atividades para que entendam o conteúdo, saber como avaliar esses alunos, saber como trabalhar com a família e assim segue o rol de temas elencados.

Naproblematização sobre as políticas públicas naárea, permanece a necessidade de discussão sobre 0 aligeiramento e mercantilização da formação de professores; sobre o direito a uma escola que socialize conhecimentos; sobre as condições de trabalho no cotidiano escolar. Permanece a percepção de que a inclusão é um mito: é uma "solução imaginária para tensões, conflitos e contradições que não encontram caminhos para serem resolvidos no nível da realidade" (CHAUÍ, 2006, p. 9).

Ao se refletir sobre a formação de professores se faz necessário estudar as tensões, os conflitos, os desafios dessa trama no drama cotidiano da vida, da escola. O u seja, estudar os limites da chamada inclusão dentro de um sistema que tem sua gênese na exclusão. E ao conhecer esses limites, trabalhar no processo de emancipação.

Rev. Diálogo Educ., Curitiba, v. 9, n. 28, p. 621-632, set./ dez. 2009 
632 CAIAD , K. R. M.; MARTINS, L. de S.; ANTONIO, N. D. R.

\section{REFERÊNCIAS}

BO URDIEU, P. A misénia do mundo. Petrópolis: Vozes, 1997.

BRA SIL. Plano Nacional de E ducação. Brasilia: Ministério da Educação, 2001. D isponível em: <http:// planipolis.iiep.unesco.org/ upload/ Brazil/ Brazil\%20Plano\%20nacional\%20de\%20educacao.pdf>. Acesso em: 15 jul. 2008.

. Política Nacional de E ducação Especial na Perspectiva da E ducação Inclusiva. Brasília: Ministério da Educação, 2008. Disponível em: <http:/ / portal.mec.gov.br/ arquivos/ pdf/ politicaeducespecial.pdf>. Acesso em: 15 jul. 2008. CAIADO, K. R. M.; MARTINS, L. S.; ANTÔNIO, N. D. R. A formação do professor para educação especial no ensino superior: tema em debate. In: CONGRESSO PAULISTA SOBRE FORMAÇÃO DE EDUCAD ORES, 9., 2007, São Paulo. Livro Eletrônico... São Paulo: UNESP, 2007. p. 96-102. CD-ROM.

CHAUÍ, M. Brasil: mito fundador e sociedade autoritária. São Paulo: Fundação Perseu Abramo, 2006.

D IEG UEZ, F. Professores, elo frágil da educação. Estudos Avançados, São Paulo, v. 21, n. 60, p. 105-113, 2007.

MICHELS, M. H. Práticas de ambigüidades estruturais e a reiteração do modelo médico-psicológico: a formação de professores de educação especial na UFSC. In: BUENO, J. G. S.; MENDES, G. M. L.; SANTOS, R. A. Deficiência e escolarização: novas perspectivas de análise. Araraquara, SP: Junqueira \& Marin; Brasilia: Capes, 2008. p. 9-47.

ORGANIZAÇÃO DAS NAÇÕES UNIDAS - ONU. Convenção sobre os direitos das pessoas com deficiência, aprovada pela Assembléia Geral da ONU, dezembro de 2006. Disponível em: <http:/ / www.bengalalegal.com/ onu.php>. Acesso em: 15 jul. 2008.

SAVIANI, D. A pedagogia no Brasil: história e teoria. Campinas: Autores Associados, 2008.

Recebido: 12/ 11/ 2008

Received: 11/ 12/ 2008

Aprovado: 02/ 12/ 2008

A pproved: $12 / 02 / 2008$

Revisado: 15/ 09/2009

Reviewed: 09/ 15/ 2009

Rev. Diálogo Educ., Curitiba, v. 9, n. 28, p. 621-632, set./ dez. 2009 